\title{
Using RESOURCESAT-1 data for determination of snow cover and snowline altitude, Baspa Basin, India
}

\author{
Rakesh KAUR, ${ }^{1}$ Anil V. KULKARNI, ${ }^{2}$ B.S. CHAUDHARY ${ }^{3}$ \\ ${ }^{1}$ National Technical Research Organization, New Delhi 110067, India \\ E-mail: rkaur.rana@gmail.com \\ ${ }^{2}$ Space Applications Centre, Indian Space Research Organisation, Ahmedabad 380015, India \\ ${ }^{3}$ Department of Geophysics, Kurukshetra University, Kurukshetra 136119, India
}

\begin{abstract}
This paper presents a method for deriving the snowline altitude using a combined analysis of terrain elevation and multispectral Advanced Wide Field Sensor (AWiFS) data from the RESOURCESAT-1 satellite, launched by India on 17 October 2003. AWiFS is a unique instrument capable of acquiring imagery of the world repeatedly every 5 days with very high radiometric resolution. It provides a wide swath width, which is very useful for snow-cover mapping. Snowline altitude is a good indicator of snow coverage. Snowline altitude for the period from October 2004 to June 2005, and from October 2006 to June 2007, is determined for the Baspa Basin, which is located in the Kinnaur district of Himachal Pradesh, India. It is observed that snowline altitude is generally higher during the year 2006/ 07 than during 2004/05, except in December 2006 and March 2007. The results obtained with the analysis presented here are validated using available meteorological data and are found to be satisfactory. This thus establishes a method that can be applied to other terrains and over longer periods of time within the coverage of the AWiFS sensor data.
\end{abstract}

\section{INTRODUCTION}

The Himalaya is one of the youngest mountain ranges in the world and accounts for $\sim 70 \%$ of non-polar glaciers. Its direct influence on the climate, hydrology and environment of the Indian subcontinent is well known. The Himalayan region has permanent snowfields, and in the winter most of the high-altitude region experiences snowfall. During summer, snowmelt is the major runoff for many rivers originating from the Himalaya, including those which are key elements of agricultural systems of South Asia. Monitoring snow-cover change is therefore essential to assess the stability of South Asia's hydrologic cycle.

As fieldwork in the Himalaya is generally hindered by harsh environmental conditions and logistical difficulties, remote-sensing techniques provide the most suitable means of monitoring changes at higher altitudes for a variety of temporal and spatial scales. Satellite remote sensing offers the opportunity to monitor and evaluate various snow parameters and processes at regional and global scales (Hall and others, 2005). The remote-sensing technique has been used extensively for snow-cover monitoring in the Himalayan region with the help of numerous satellite sensors (Kulkarni and Rathore, 2003). Snowline altitude and its projection on geographic maps of the area are important indicators of snow coverage. Snowline and snowcover variations from place to place and through time provide much information about regional climate and shorter-timescale meteorological fluctuations. However, only a few publications deal with the use of satellite data for assessing the snowline elevation (Seidel and others, 1997).

The snowline is the boundary separating snow-covered from snow-free areas. The seasonal snow cover in the Himalaya is too scattered, due to the rugged relief, to allow a straightforward mapping of the snowline. However, monitoring of the snow cover and snowline in this region is extremely important, as it provides fresh water to the agricultural systems that support a fifth to a sixth of the world's population. Despite this importance, snowlinealtitude determination in the Himalaya is poorly studied; therefore, new techniques to determine it would make a significant contribution.

Here, we demonstrate the application of satellite data in combination with a digital elevation model (DEM) of the Himalayan terrain as a means of assessing snowline elevation. The investigation of snow cover and snowlinealtitude determination is undertaken for the Baspa Basin, using data from the RESOURCESAT-1 satellite's Advanced Wide Field Sensor (AWiFS) and the Shuttle Radar Topographic Mission's (SRTM) observations of terrain elevation. The AWiFS sensor has unique capabilities for snow investigations, including high receptivity, large swath area and high saturation radiance. This study is intended as the first step towards using AWiFS data in the Himalayan region to better assess snow climatology.

\section{STUDY AREA}

The study was carried out in the Baspa Basin, located in the Kinnaur district of Himachal Pradesh, India. The river Baspa is a major tributary of the Satluj, which drains the eastern part of Himachal Pradesh. A location map is shown in Figure 1.

The Baspa Basin is highly glacierized and located in the higher-altitude range. In socio-economic terms, this basin is very important, as many hydroelectric power projects are being planned. Due to the high altitude of the basin, streamflow is mostly generated from snow- and glacier-melt runoff. Knowledge of the snow cover on a year-to-year basis and changes in snowline altitude are important decision-making parameters when planning hydroelectric power stations. 


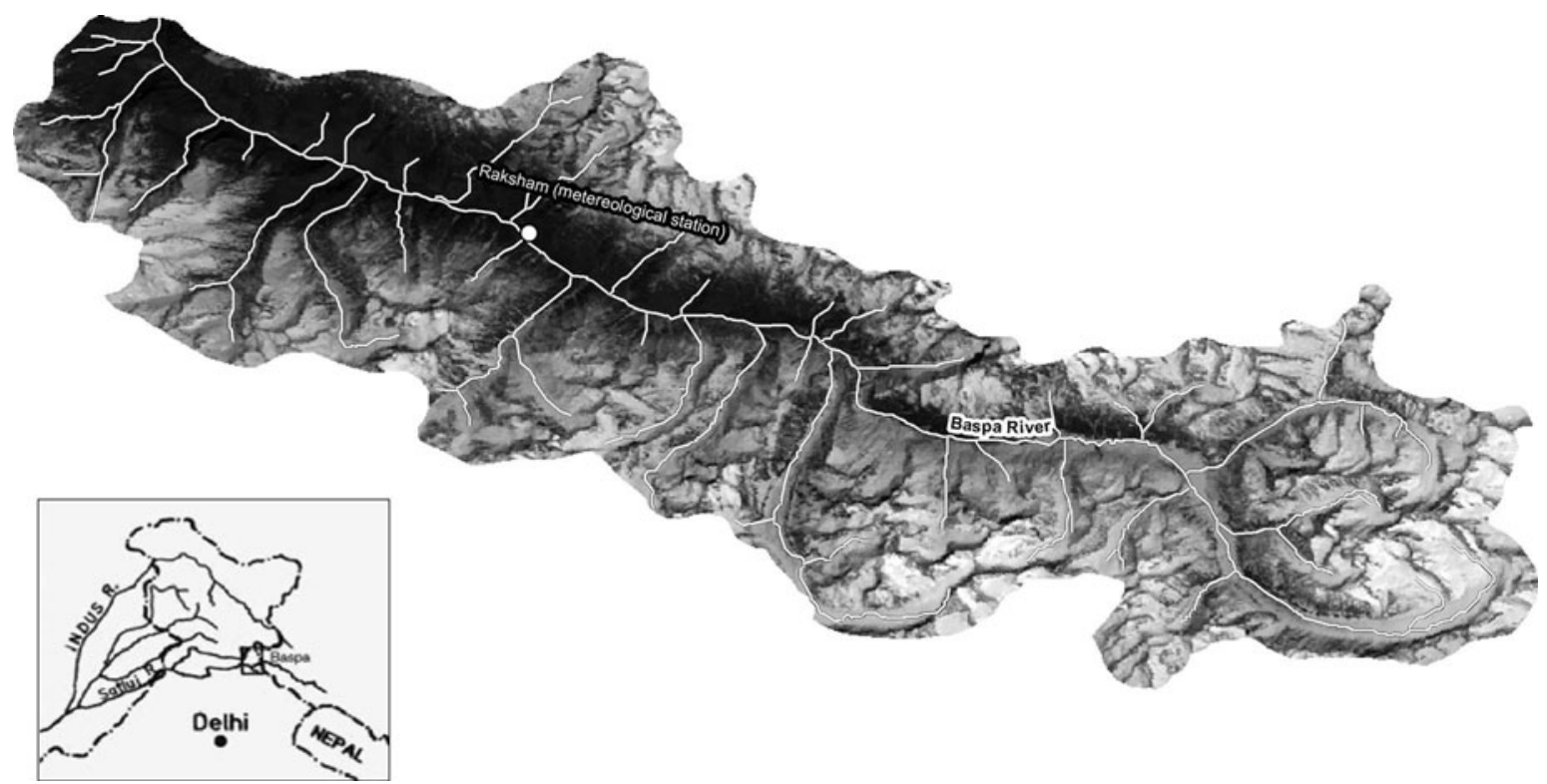

Fig. 1. Study area.

\section{METHODOLOGY}

The snowline is defined as the line delimiting an area with complete snow cover from an area free of snow. The roughness of the surface topography and spatial resolution of the remote-sensing data that determine the extent of snow cover does not allow a direct distinction of snowline in the Baspa Basin. Snowline is therefore determined using the hypsography derived from a DEM and from snow-cover maps determined by a normalized-difference snow index (NDSI) technique. Snowline altitude and the snow-cover area of the Baspa Basin determined using available satellite images from the AWiFS sensor on RESOURCESAT-1 and from the DEM are presented below.

The methodology to determine snowline altitude is described in the following three steps:

\section{Step 1. Determination of the hypsography of Baspa Basin}

An area by elevation histogram, i.e. hypsography, is determined using a DEM combined with the basin outline (Khalsa and others, 2004). We chose the SRTM digital-elevation dataset for the DEM, because it provides global coverage of the Earth's land surface, has $90 \mathrm{~m}$ spatial resolution and $\pm 15 \mathrm{~m}$ vertical accuracy. The study region is broken into areas separated by contour intervals of $100 \mathrm{~m}$, and this breakdown is used to establish the elevation zones shown in Figure 2.

Using a Geographical Information System (GIS) software package, we customized a tool used for automatic extraction of area between different elevation zones for the entire Baspa Basin. This tool generates the area/altitude distribution along with a summary table. The resultant table is further analysed to generate a graph expressing cumulative per cent area of the basin vs altitude (Fig. 3). It can be seen that the Baspa Basin lies within the elevation range $1900-6400 \mathrm{~m}$, that $\sim 98 \%$ of the basin area is located lower than $5800 \mathrm{~m}$ and that the mid-altitude of the basin is $\sim 4800 \mathrm{~m}$.

\section{Step 2. Estimation of snow cover}

The remote-sensing technique has been used extensively for snow-cover monitoring in the Himalayan region with the

Table 1. Major performance parameters of the AWiFS camera

\begin{tabular}{|c|c|c|c|c|}
\hline Parameter & \multicolumn{4}{|c|}{ Value } \\
\hline \multicolumn{5}{|l|}{ Ground sampling distance $(\mathrm{m})$} \\
\hline Across track & \multirow{2}{*}{\multicolumn{4}{|c|}{56 (nadir), 70 (off-nadir) }} \\
\hline Along track & \multirow{2}{*}{\multicolumn{4}{|c|}{$\begin{array}{l}66 \text { for an integration time of } 9.96 \mathrm{~ms} \\
740 \mathrm{~km}\end{array}$}} \\
\hline Swath (without Earth-curvature effect) & & & & \\
\hline Bands $(\mu \mathrm{m})$ & B2 & B3 & B4 & B5 \\
\hline & $0.52-0.59$ & $0.62-0.68$ & $0.77-0.86$ & $1.55-1.7$ \\
\hline Quantization (bits) & \multicolumn{4}{|c|}{10} \\
\hline Signal-to-noise ratio at saturation radiance & \multicolumn{4}{|c|}{$>512$ (for all bands) } \\
\hline Radiance setting at $100 \%$ albedo & B2 & B3 & B4 & B5 \\
\hline$\left(\mathrm{mW} \mathrm{cm}^{-2} \mathrm{Sr}^{-1} \mu \mathrm{m}^{-1}\right)$ & 53 & 47 & 31.5 & 7.5 \\
\hline Square-wave response (\%) & B2 & B3 & B4 & B5 \\
\hline & $>30$ & $>30$ & $>20$ & $>20$ \\
\hline Band-to-band registration (pixels) & \multicolumn{4}{|c|}{$\leq \pm 0.25$} \\
\hline
\end{tabular}




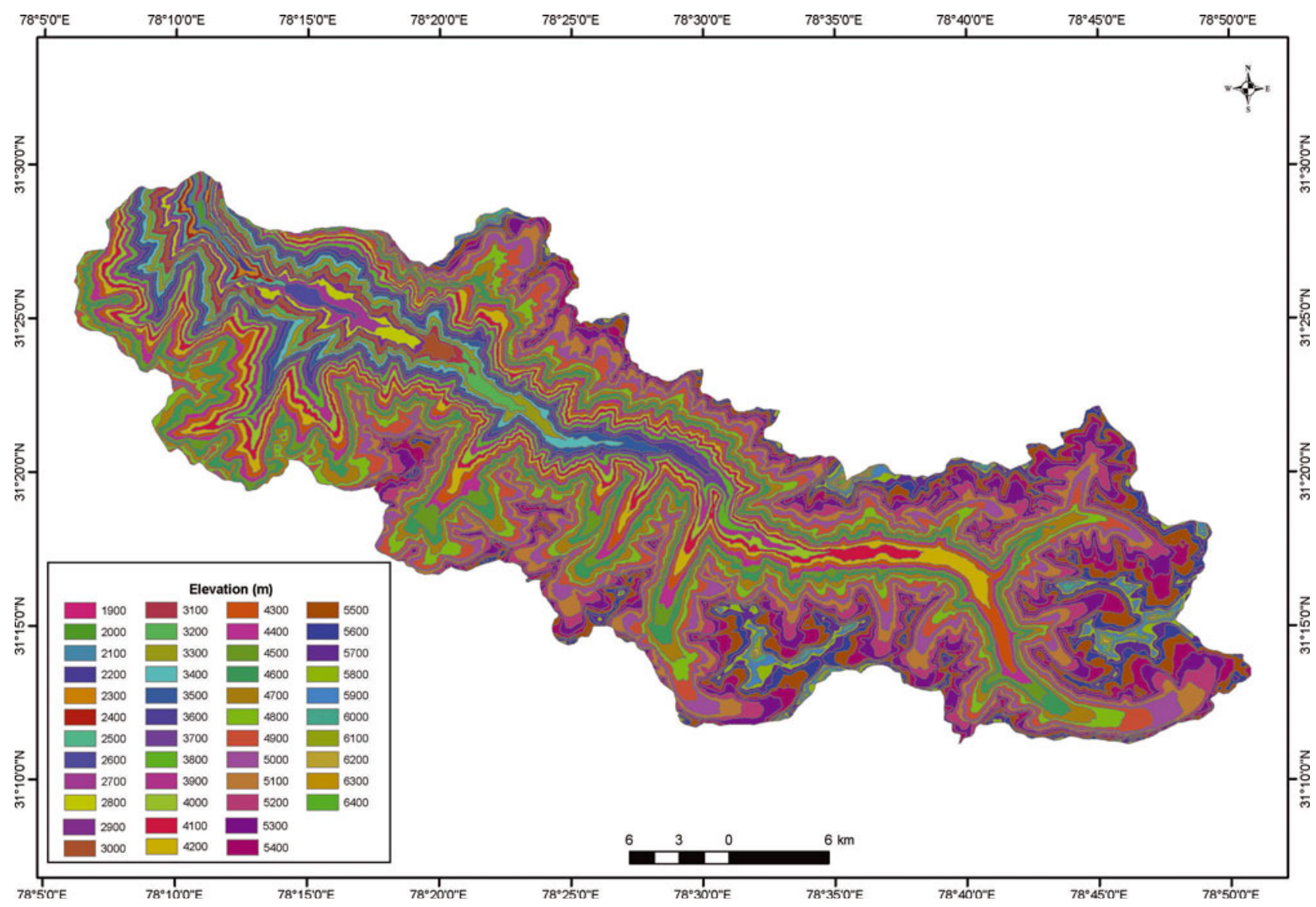

Fig. 2. Elevation zones of the study region, in $100 \mathrm{~m}$ intervals.

help of numerous satellite sensors (Kulkarni and Rathore, 2003). The major difficulties in developing an automated technique to monitor snow cover in the Himalayan region are the effects of mountain shadows and the confusing signature of snow and cloud in the visible and near-infrared. To overcome these problems we used a NDSI method. This technique can be utilized due to the availability of green and shortwave infrared bands in the AWiFS sensor of RESOURCESAT-1 (Hall and others, 1995). It has the advantage over previous techniques that it can detect snow even under mountain shadows and is not influenced by topographic conditions (Kulkarni and others, 2006). AWiFS is a unique sensor, providing global data with a spatial resolution of $56 \mathrm{~m}$ at 5 day intervals (Kirankumar, 2003). The sensor characteristics are given in Table 1.

In order to determine the position of the snowline, periodic snow-cover mapping was carried out with a 5 day frequency. A total of 54 AWiFS scenes were analysed and the snow cover determined using the NDSI technique. The AWiFS image of 11 April 2007 superimposed on the DEM is shown in Figure 4.

For the study area, snow extent was generated from October 2004 to June 2005 and October 2006 to June 2007.

\section{Step 3. Determination of snowline altitude}

The term 'snowline' is used to mean different things, depending on the context in which it is used. Here it is the transient snowline, which refers to the boundary between the snow-covered surface and a bare surface at a given time (Østrem, 1974). For the Baspa Basin, the mean monthly snowline altitude is determined by comparing Figures 3 and 5. The results are presented in Figure 6.

\section{RESULTS AND DISCUSSION}

Figure 5 shows that overall snow cover in the year 2006/07 is less than that of 2004/05. The melt season begins in March and continues until June for both years. Both years follow the same ablation pattern, ablation being higher in 2006/07

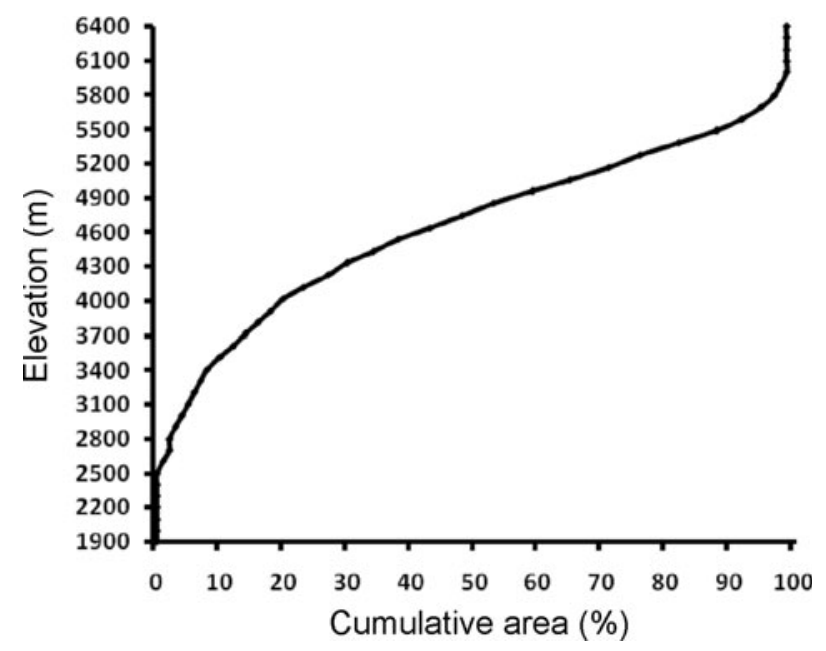

Fig. 3. Area/altitude distribution curve for the Baspa Basin. 


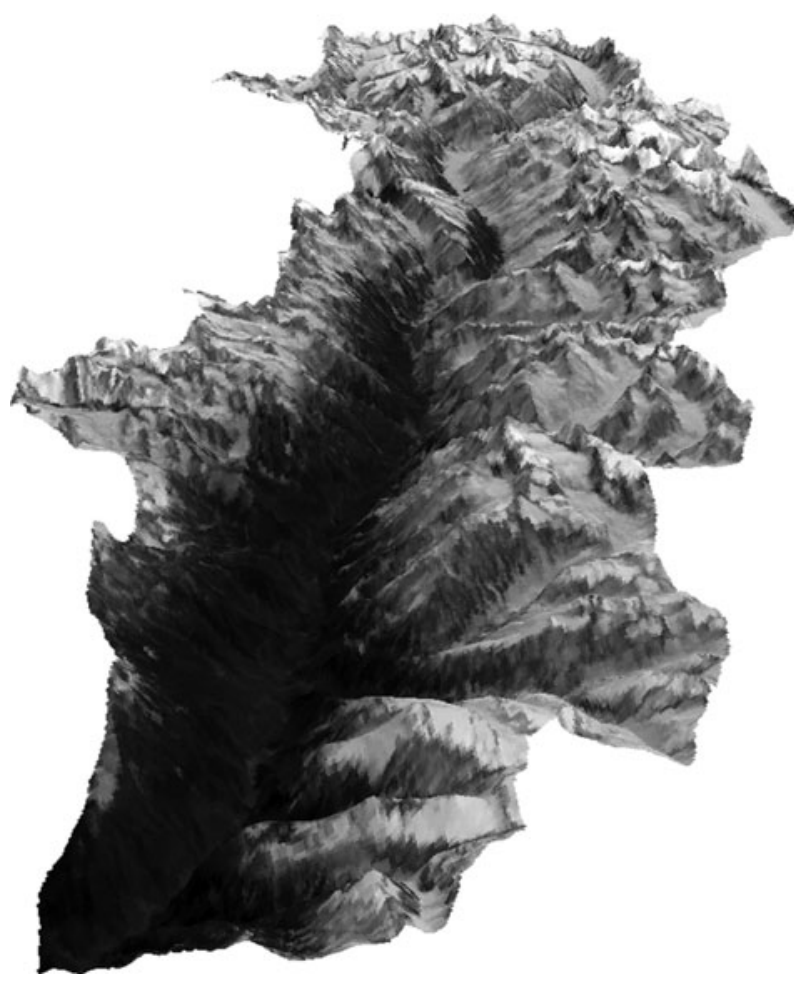

Fig 4. Perspective view of Baspa Basin on 11 April 2007, derived from the AWiFS imaging camera.

than in $2004 / 05$. It can be seen that the mean snow cover for June 2007 is $18 \%$ less than in June 2005 .

Figure 6 shows that the snowline altitude is generally higher during 2006/07 than during 2004/05, except in December 2006 and March 2007. The lowest snowline altitude was observed to be 2425 ma.s.l. in February of the year 2004/05 and 2846 m a.s.I. in March of 2006/07.

To assess the performance of our approach, we consider meteorological parameters, such as precipitation and temperature. Snowfall data at Raksham in the Baspa Basin were analysed for the period from October 2004 to June 2005 and from October 2006 to June 2007; the results are given in Table 2.

During 2004/05, snowfall is maximum in February 2005, and during 2006/07 the maximum is in March 2007. It

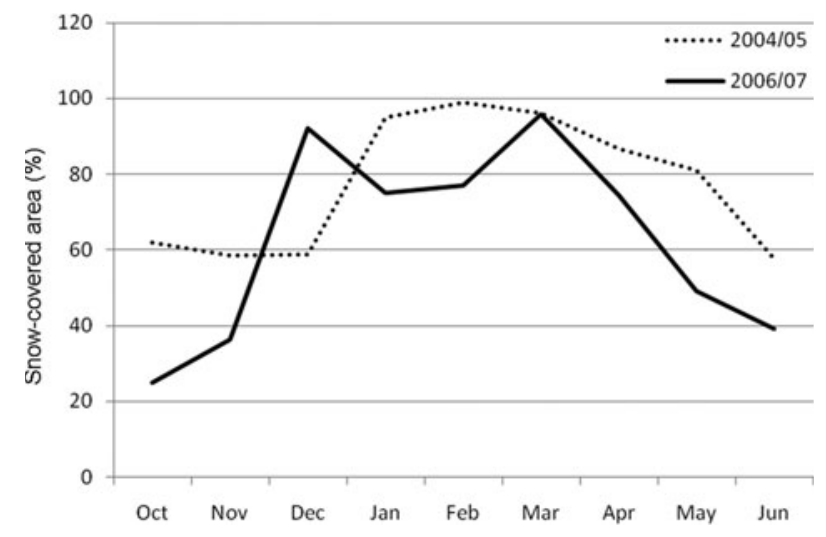

Fig. 5. Snow-covered area (monthly mean, percentage of total area) for the periods from October 2004 to June 2005 and from October 2006 to June 2007.

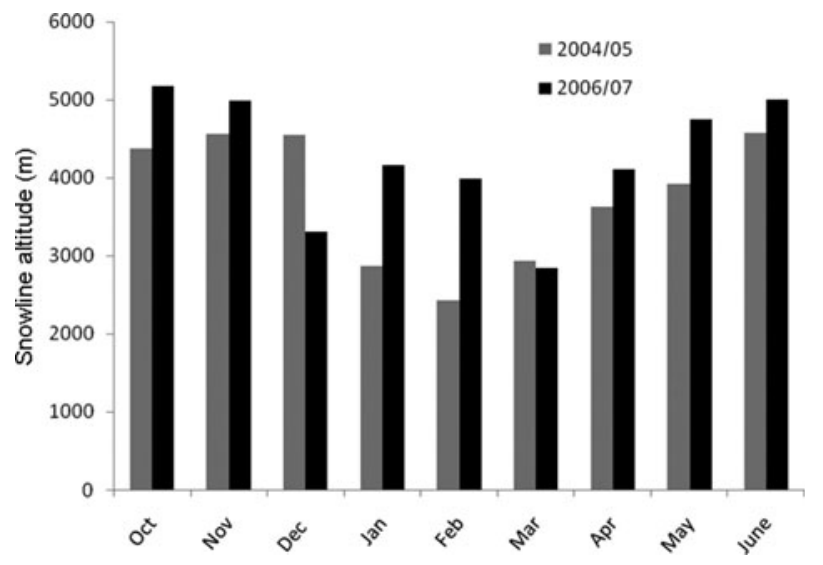

Fig. 6. Snowline altitude for the periods from October 2004 to June 2005 and from October 2006 to June 2007.

follows that snowline altitude will be at a minimum during these months, which is indeed confirmed by Figure 6. Also, snowfall is generally less during 2006/07 than during 2004/ 05, except in December 2006 and March 2007. This indicates higher snowline altitude during 2006/07, except in December 2006 and March 2007. The lower snowline elevation corresponds to the greater initial accumulation of snow, and the higher elevation corresponds to the lower initial accumulation of snow. Comparison of the snowfall data in Table 2 with the snowline altitudes in Figure 6 supports the applicability of our method for determining snowline altitude. Similarly, Kaur and others (2009) showed that air temperature during the melt season correlated well with the ablation patterns.

\section{SUMMARY}

A three-step approach for snowline-altitude determination using satellite remote sensing and a digital elevation model has been presented. The results show good correspondence with precipitation data. Snowline is an important indicator of snow coverage, and, when viewed over a large area for many decades, the elevation shift of the snowline indicates certain climate behaviour, either to a colder or a warmer climate. The periodical study of spatio-temporal variations of snowline can help in assessing the hydrologic cycle balance that will affect the large human populations of South Asia. The results presented here for the Baspa Basin indicate that

Table 2. Monthly average snowfall (m) at Raksham in the Baspa Basin

\begin{tabular}{lcc}
\hline & $2004 / 05$ & $2006 / 07$ \\
\hline October & 1.1 & 0 \\
November & 0.8 & 0.6 \\
December & 0.7 & 3.3 \\
January & 3.7 & 0 \\
February & 4.7 & 3.2 \\
March & 1.4 & 6.3 \\
April & 0.6 & Not available \\
May & 0.1 & Not available \\
June & 0 & \\
\hline
\end{tabular}


monitoring snow-cover depletion and the subsequent rise in snowline is possible. This will be useful in decision-making on hydroelectric power station construction. This study, therefore, can be considered as an initial approach in the assessment of snow climatology that is applicable to the Himalayan region. Further assessment of the methodology, and further identification of trends in snow climatology, require extended databases, including several more years of AWiFS data.

\section{ACKNOWLEDGEMENTS}

Comments by two anonymous reviewers helped to improve the manuscript. We thank the Scientific Editor D. MacAyeal for his guidance in the review process.

\section{REFERENCES}

Hall, D.K., G.A. Riggs and V.V. Salomonson. 1995. Development of methods for mapping global snow cover using Moderate Resolution Imaging Spectroradiometer (MODIS) data. Remote Sens. Environ., 54(2), 127-140.

Hall, D.K., R.E.J. Kelly, J.L. Foster and A.T.C. Chang. 2005. Hydrological applications of remote sensing: surface states: snow. In Anderson, M.G., ed. Encyclopedia of hydrological sciences. Chichester, Wiley, 3456.

Kaur, R., D. Saikumar, A.V. Kulkarni and B.S. Chaudhary. 2009. Variations in snow cover and snowline altitude in Baspa Basin. Current Sci., 96(9), 1255-1258.

Khalsa, S.J.S., M.B. Dyurgerov, T. Khromova, B.H. Raup and R. Barry. 2004. Space-based mapping of glacier changes using ASTER and GIS tools: learning from Earth's shapes and colors. IEEE Trans. Geosci. Remote Sens., 42(10), 2177-2183.

Kirankumar, A.S. 2003. Advanced wide field sensor (AWiFS). SAC Courier 28, 3-7.

Kulkarni, A.V. and B.P. Rathore. 2003. Snow cover monitoring in Baspa Basin using IRS WiFS data. Mausam, 54(1), 335-340.

Kulkarni, A.V., S.K. Singh, P. Mathur and V.D. Mishra. 2006. Algorithm to monitor snow cover using AWiFS data of RESOURCESAT- 1 for the Himalayan region. Int. J. Remote Sens., 27(12), 2449-2457.

Østrem, G. 1974. Present alpine ice cover. In Ives, J.D. and R.G. Barry, eds. Arctic and Alpine environments. London, Methuen, 225-250.

Seidel, K., C. Ehrler, J. Martinec and O. Turpin. 1997. Derivation of statistical snowline from high resolution snow cover mapping. In Proceedings of the 1st EARSeL Workshop on Remote Sensing of Land Ice and Snow, University of Freiburg, Germany, 17-18 April 1997. Paris, European Association of Remote-Sensing Laboratories. 31-36. 